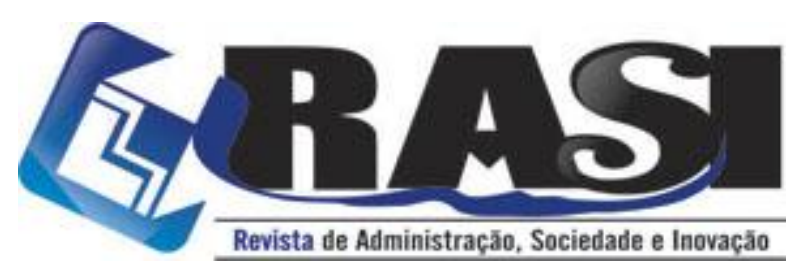

http://www.rasi.uff.br

RASI, Volta Redonda/RJ, v.5, n.1, pp.1-5, jan./abr. 2019.

\title{
Editorial: Um Novo Ciclo
}

Márcio Moutinho Abdalla (UFF) - marcioabdalla@id.uff.br

Vanessa da Silva Garcia (UFF) - vanessagarcia@id.uff.br

Ricardo César da Silva Guabiroba (UFF) - ricardocesar@id.uff.br

Raquel de Souza Corrêa (UFF) - raquelcorrea.adm@gmail.com

\section{Universidade \\ T10 Federal}

R. Desembargador Ellis Hermydio Figueira, 783, Bloco A, sl. 218, Aterrado.

27213-145 - Volta Redonda, RJ - Brasil wWw.uff.br 


\section{Editorial: Um Novo Ciclo}

É possível argumentar que em pelo menos cinco dos oito editoriais publicados pela RASI (contando com esse), a temática "transparência no processo editorial" tenha sido abordada, ou como tópico central, ou de forma tangencial. Acreditamos que o editorial seja um meio eficaz de participar leitores sobre o desenvolvimento do periódico, suas políticas, práticas e ambições. Nessa primeira edição de 2019, não tomamos rumo diferente. Particularmente gostaríamos de apresentar três novidades e alguns dados referentes ao ano de 2018.

A primeira novidade refere-se à abertura formal de novas sessões no periódico. Temos tradicionalmente publicado artigos científicos e, por vezes, ensaios teóricos. Já havíamos recebido alguns Artigos Tecnológicos e alguns Casos para Ensino, mas somente nesse número tivemos a oportunidade de publicar dois dos (ótimos) Casos para Ensino aprovados. Mantemos expectativas de receber mais submissões de trabalhos de cunho tecnológico, pois acreditamos muito nessa vertente e temos estimulado o envio de bons trabalhos sob essa abordagem. Desta forma, a partir desse número, além da tradicional sessão de "Artigos Científicos", trabalharemos com as sessões de "Artigos Tecnológicos"; "Casos para Ensino" e "Ensaios Teóricos", quando contarmos com trabalhos aprovados nas respectivas sessões.

Outra importante mudança é que a partir dessa edição a RASI passa a ser publicada quadrimestralmente. Acreditamos que o atual volume de submissões, associado à nossa taxa de seletividade, torne plenamente viável esse importante passo. A publicação de três edições por ano é um dos requisitos essenciais para que a RASI se faça presente em indexadores como o Redalyc que, por sua vez, é requisito para alcançar estratos mais elevados pela avaliação Capes, por meio de sua classificação Qualis. Acreditamos na relevância desta escalada, não por questões de rankeamento ou pela própria estratificação em si, mas pelo potencial impacto produzido pela RASI a partir dela.

Fechando as novidades dessa edição, anunciamos oficialmente a mudança dos editores. Em maio de 2019, fecharemos o ciclo de quatro anos a frente da editoria da RASI, período que compreende sua concretização - de projeto para "produto"; o lançamento de oito edições sem nenhum atraso; a "sobrevivência" a uma conturbada invasão de hackers aos servidores da universidade; a honrada participação em diversos fast tracks e numa prova do teste ANPAD; a publicação de 46 trabalhos de autores do Brasil, Europa, Ásia e América Latina; além de outras importantes conquistas, que são sempre divididas por meio dos editoriais. Aproveito o espaço para agradecer imensamente o empenho dos meus pares, os editores associados Prof. Ricardo César da Silva Guabiroba e Professora Vanessa da Silva Garcia; à nossa bolsista Raquel de Souza Corrêa; aos colegas do Conselho Editorial e do Corpo Editorial, que nos acompanharam ao longo desses anos; aos comprometidos avaliadores; aos brilhantes autores; e aos prestigiados leitores, que são a razão de ser do periódico.

Após fecharmos o ciclo com os agradecimentos, abrimos um novo ciclo dando boas-vindas ao novo editor científico da RASI, o prof. Marcelo Gonçalves do Amaral, que foi devidamente aprovado pelo Conselho Editorial vigente, e detém competências 
importantes para o avanço da RASI. Até maio a equipe atual permanecerá, como forma de pavimentarmos um processo de transição suave e consciente. Desta forma, a próxima edição será concebida por várias mãos, embora seja assinada pelo novo corpo de editores. Desejamos todo o sucesso à nova equipe e que a RASI continue trilhando esse virtuoso caminho.

Por falar em trajetória, aproveitamos esse espaço para compartilhar com a comunidade acadêmica alguns importantes dados da RASI, sobretudo referentes ao ano de 2018, parte dos quais foram responsáveis pele decisão de ampliarmos o número de edições por ano. Podemos iniciar a explanação por meio da evolução no número de submissões por ano, conforme apresentado no gráfico 1.

\section{Gráfico 1: Evolução das Submissões}

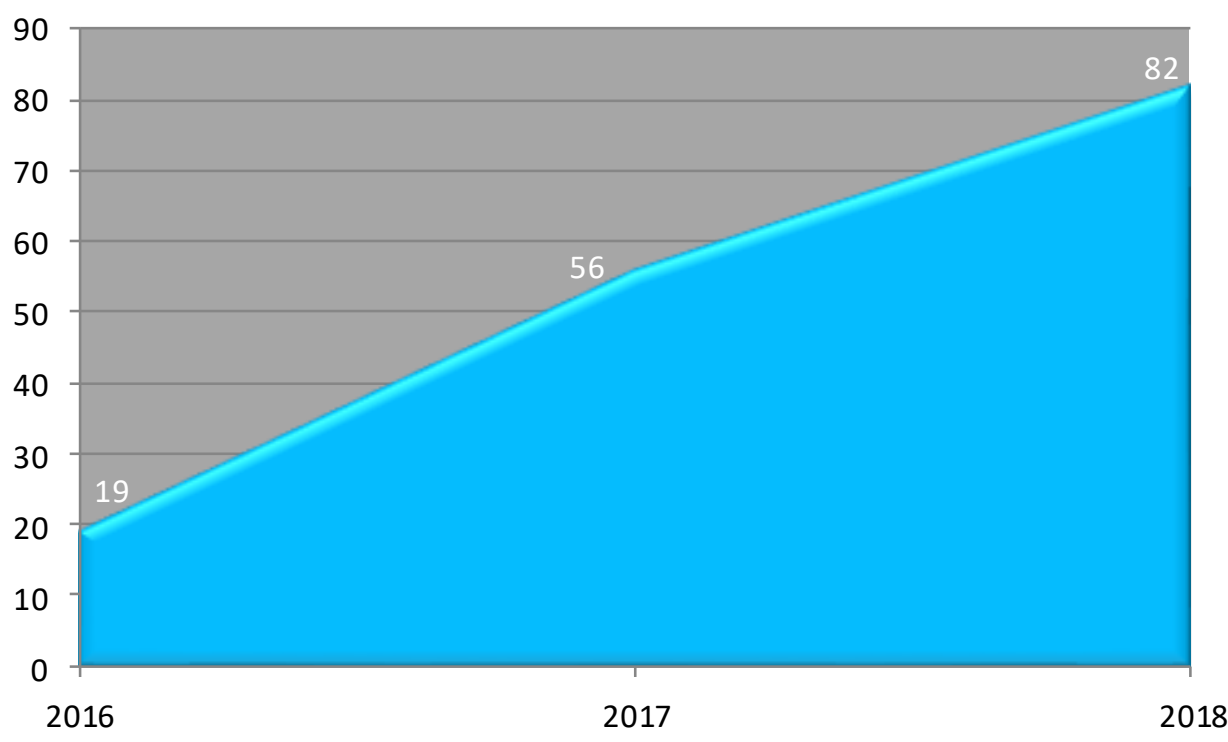

Fonte: Dados do Open Journal Systems

Em 2018, recebemos, em média, sete submissões por mês. Conforme previsto em um de nossos editoriais (Abdalla, 2016), o aumento no número de submissões possibilita maior rigor na avaliação dos trabalhos, implicando diretamente no aumento da qualidade e da relevância do que é publicado. Como consequência, a maior seletividade dos trabalhos implica diretamente na taxa de aceitação dos artigos submetidos. Em 2018, essa taxa foi de aproximadamente $37 \%$. Em outras palavras, do total de trabalhos submetidos, 63\% foram recusados. Outro importante indicador de qualidade é a taxa de endogenia da RASI. Em 2018, do total de trabalhos publicados, apenas $10 \%$ são de autoria ou coautoria de docentes, discentes e/ou pesquisadores da UFF. Isso significa que a política editorial da RASI, que preconiza diversidade institucional, vem sendo plenamente cumprida.

Por fim, um dos aspectos que muito nos orgulha são os prazos editoriais. Num contexto em que periódicos chegam a gastar até 180 dias com a avaliação preliminar do editor (desk review), conseguimos manter um prazo médio de 14 dias para essa fase. A 
partir da aceitação na fase de desk review e consequente designação aos pares para avaliação nos moldes double blind review, o tempo médio de resposta da RASI tem sido de 78 dias. Significa que, nesta etapa, os autores já obtêm resposta em relação à avaliação por pares - se o trabalho foi recusado, aceito para publicação, ou requer modificações. Naturalmente trata-se de um prazo médio, podendo variar para mais ou menos, mas de certo é um prazo bastante razoável, comparável às melhores práticas de publicação.

Abrindo essa edição, apresentamos o artigo "A lógica contemporânea das relações de trabalho e o discurso proferido por uma empresa de cosméticos brasileira: legitimando uma ideologia" das autoras Luana Sodré da Silva Santos e Gabriela Izabel de Alvarenga, ambas da UFRRJ. Por meio da teoria sobre as formas de operação da ideologia, de Thompson (1995), as autoras analisam qualitativamente as estratégias empresarias discursivas adotadas por uma empresa em relação às suas consultoras, como forma de naturalizar práticas de dominação nas relações de trabalho.

No segundo trabalho, sob o título "Cooperação e Intersetorialidade na Política sobre Drogas em São Paulo", Renato Eliseu Costa (SENAC/SP) e Anny Karine de Medeiros (FGV) discutem políticas públicas de combate às drogas, por meio da análise dos programas "Crack: é Possível Vencer", "Recomeço" e "De Braços Abertos", referentes ao enfrentamento do problema na chamada "Cracolância", em São Paulo. Apesar dos tímidos avanços observados, os autores identificam dificuldades no processo de instituir práticas intersetoriais que extrapolem ações temporárias e circunscritas geograficamente. Segundo os autores, a descentralização federativa é uma das principais barreiras de articulação para alcance de resultados mais significativos.

O terceiro artigo mantém-se sob a temática de políticas públicas, contudo concentra-se em discutir "A Política Nacional da Saúde do Idoso em perspectiva". Por meio de uma investigação bibliométrica em artigos publicados entre os anos de 2013 a 2017, os autores Érika Loureiro Borba (UNIVÁS), Fabrício Molica de Medonça (UFSJ), Kelly Aparecida Torres (UNIPTAN) e Pablo Luiz Martins (UNIVÁS/UFSJ) buscaram compreender o processo de implementação da Política Nacional de Saúde do Idoso. Como principal contribuição, o estudo destaca o imperativo de revisão da nova realidade demográfica brasileira, paralelamente ao conceito de envelhecimento ativo e seus indicadores, como forma de melhor adequação das políticas à realidade desse grupo social. Os autores também defendem maior articulação entre as esferas governamentais, como forma de assegurar mais efetividade nos processos de implementação da política.

Em "Gestão da Inovação: O caso da celulose Irani (SC)", Nelson Santos Machado (UNOESC), Gabriela Terezinha Luchese (UFSC) e Fernando Fantoni Bencke (UNOESC) propõem-se, por meio de um estudo de caso, a compreenderem o processo de implantação da gestão da inovação na empresa Celulose Irani. A descrição do processo de gestão da inovação da empresa estudada, sob uma análise crítica, configurase numa das principais contribuições do trabalho, que também identifica a organização e a estruturação da Celulose Irani adequadas ao desenvolvimento de atividades de inovação, contudo com espaço para aprimoramentos.

$\mathrm{Na}$ sessão de Casos para Ensino, o trabalho "Vamos Expandir um Negócio Inovador? Caso de Ensino", de Eliana Andréa Severo (UnP), Julio Cesar Ferro Guimarães (UnP), Vanessa Faedo Serafin (IMED) e Mauro Sergio Vanin (IMED), 
fundamenta-se em dados reais para discutir a situação de mercado de um fabricante de Purificadores de Água, que também gerencia o serviço de fornecimento e franquia de água purificada a granel. A problemática que norteia o caso concentra-se no processo de tomada de decisão, sobretudo de uma empresa jovem, que decidiu fabricar ao invés de importar máquinas purificadoras. O principal dilema gira em torno da decisão de expansão dos serviços nacionalmente e o surgimento de concorrentes. $\mathrm{O}$ caso pode ser empregado em disciplinas relacionadas à estratégia, tanto em nível de graduação, quanto de pós-graduação lato sensu, especialmente em cursos de administração.

Fechando essa edição, apresentamos o caso "Gestão e Improvisação em um Festival Cultural na Bahia", de Fernanda Paquelet Moreira Barbosa e Eduardo Davel, ambos da UFBA. A partir de uma investigação empírica baseada em prolongada e sistemática observação participante frente ao processo de organização e gestão em vários eventos culturais na Bahia, os autores conceberam esse caso para ensino. Destaca-se seu objetivo de suscitar aprendizagem sobre e relevância da improvisação para as organizações e gestores contemporâneos; sobre o papel da imperfeição, cooperação e competição para a prática da improvisação organizacional e os desafios e competências de improvisação para gestores. O caso evidencia a importância da improvisação organizacional para a gestão das organizações contemporâneas.

Reiteramos todos os agradecimentos feitos neste texto, desejando uma excelente leitura, um 2019 esplêndido e um novo ciclo virtuoso para a RASI!

\section{Referências}

Abdalla, M. (2016). A Salutar busca pela Transparência em Pesquisas. Revista de Administração, Sociedade $\quad e \quad$ Inovação, $\quad 2(1), \quad$ 1-3. https://doi.org/10.20401/rasi.2.1.94 